\title{
Virulence Factors Associated with Pediatric Shigellosis in Brazilian Amazon
}

\author{
Carolinie Batista Nobre da Cruz, ${ }^{1}$ Maria Carolina Scheffer de Souza, ${ }^{2}$ \\ Paula Taquita Serra, ${ }^{2}$ Ivanildes Santos, ${ }^{1}$ Antonio Balieiro, ${ }^{1}$ Fabio Alessandro Pieri, ${ }^{3}$ \\ Paulo Afonso Nogueira, ${ }^{1}$ and Patrícia Puccinelli Orlandi ${ }^{1}$ \\ ${ }^{1}$ Instituto Leônidas e Maria Deane-Fiocruz Amazônia, Rua Terezina 476, Adrianópolis, \\ 69.057-070 Manaus, AM, Brazil \\ ${ }^{2}$ Programa de Pós Graduação em Imunologia Básica e Aplicada (PPGBA-UFAM), \\ Avenida General Rodrigo Octávio 6200, Coroado I, 69.077-000 Manaus, AM, Brazil \\ ${ }^{3}$ Departamento de Ciências Básicas da Saúde, Universidade Federal de Juiz de Fora, Câmpus Governador Valadares, \\ Rua Israel Pinheiro 2000, Bairro Universitário, 35010177 Governador Valadares, MG, Brazil
}

Correspondence should be addressed to Patrícia Puccinelli Orlandi; patricia_orlandi@amazonia.fiocruz.br

Received 28 November 2013; Accepted 9 April 2014; Published 29 April 2014

Academic Editor: Angel Cataldi

Copyright (C) 2014 Carolinie Batista Nobre da Cruz et al. This is an open access article distributed under the Creative Commons Attribution License, which permits unrestricted use, distribution, and reproduction in any medium, provided the original work is properly cited.

\begin{abstract}
Shigellosis is a global human health problem and the incidence is highest among children. In the present work, main Shigella virulence genes was examined by PCR and compared to symptoms of pediatric shigellosis. Thirty Shigella isolates were identified from an etiologic study at which 1,339 children ranging 0-10 years old were enrolled. S. flexneri was the most frequent species reaching $60.0 \%$ of isolates, $22.2 \%$ were S. sonnei, and $6.6 \%$ were both S. dysenteriae and S. boydii. All Shigella infected children had diarrhea, but not all were accompanied by others symptoms of bacillary dysentery. Among major virulence genes, the PCR typing revealed $i p a B C D$ was present in all isolates, followed by $I p a H 7.8$, set- $1 A$, set- $1 B$, sen/ospD3, virF, and invE. The pathogenic potential of the ShET-1B subunit was observed in relation to dehydration $(P<0.001)$ and ShET-2 related to the intestinal injury $(P=0.033)$ evidenced by the presence of bloody diarrhea. Our results show associations among symptoms of shigellosis and virulence genes of clinical isolates of Shigella spp.
\end{abstract}

\section{Introduction}

Shigella spp. is Gram-negative bacilli of the Enterobacteriaceae family that are perfectly adapted to colonize the host intestine subverting the host's defenses in their favor [1-4].

The genus Shigella encompasses four subgroups historically treated as species: Shigella flexneri, Shigella boydii, Shigella sonnei, and Shigella dysenteriae [5]. These species are the etiological agents of bacillary dysentery or shigellosis, manifested by fever, small volume of bloody, mucoid stools abdominal cramps; and mucoid, bloody diarrhea $[1,6]$. Other clinical manifestations range between nausea, vomiting, and dehydration. Depending on the virulence potential of the strain and the nutritional status of the individual, shigellosis can progress to severe disease when accompanied by rectal tenesmus, with neurological symptoms such as headache and lethargy [1].

Shigella virulence is based on the presence of a large virulence inv plasmid, carrying an operon that encodes the type III-secretion-system (T3SS) responsible for bacterial entry $[7,8]$. The ial gene is found on inv plasmid and invasionrelated processes [9]. The T3SS is composed of several proteins, including a needle shape oligomer anchored in the protein complex which connects the inner and outer bacterial membranes. The tip of the needle is oligomer composed for invasion plasmid antigens, ipaB, $i p a C$, and $i p a D$ [6-9]. The 
$i p a H$ gene is present as multiple copies, five on large plasmid and seven on chromosome. One of five copies, the ipaH7.8, plays a role in modulating the inflammatory response elicited by infection and shares a conserved C-terminal novel E3 ligase (C-term-E3-ligase) and variable $\mathrm{N}$-terminal leucinerich repeat (LRR) domains [10].

Others genes are important bacterial pathogenicity factors in the intestinal tract, such as the enterotoxins that have significant enterotoxic activity in vitro when tested in rabbit ileal loops and Ussing chambers [1]. Shigella strains produce distinct enterotoxins: Shigella enterotoxin 1 (ShET1) chromosome encoded by $\operatorname{set} 1 A$ which is present in all S. flexneri 2a. Shigella enterotoxin 2 (ShET-2) encoded by gene sen/ospD3 located on a large plasmid associated with virulence of Shigella and found in many, but not all, Shigella of different serotypes and also in enteroinvasive Escherichia coli (EIEC) $[9,11]$. And two distinct Shiga toxins (Stx-1 and Stx-2) are encoded by chromosomal genes and expressed by $S$. dysenteriae and similar to the Shiga-like toxins of enterohemorrhagic E. coli [1].

The mechanisms of main pathogenic factors of Shigella are well stablished; however, studies focusing association between pathogenicity factors and shigellosis symptoms in human are scarce $[12,13]$. In this work, the major virulence genes of Shigella species derived from pediatric bacillary dysentery were examined for PCR and the goal of this study was to investigate the relationship with symptoms of shigellosis.

\section{Material and Methods}

Patients and Samples. During a period from August 2007 to December 2008, stool specimens were collected from 1339 children ranging 0-10 years old who sought treatment at three hospitals, in Manaus, in the center of Brazilian Amazon, and transferred to a clinical microbiology laboratory. An axillary temperature higher than $37.8^{\circ} \mathrm{C}$ was considered fever when determined at the time of clinical assessment or as reported by the child's guardian. Dehydration was diagnosed by the attending medical professional. The presence or absence of vomiting was reported by the individual responsible for the clinical evaluation. The child's guardian was first informed about the research and asked to participate by filling out a consent form and a case report form (Ethics Committee of the Federal University of Amazonas 266/206). The inclusion criteria were as follows: the age of the patients was in the range of $0-10$ years old, the patients had diarrhea that lasted 7 days, and blood was evident by stool examination with a fecal occult blood (FOB) test using the Feca-Cult Kit (Inlab diagnostica). The present study was designed to isolate Shigella strains from clinical samples of patients with bloody diarrhea by culture methods and characterize them by appropriate biochemical and serological tests.

Bacterial Culture, Isolation, and Antibiogram. Lactose nonfermenting colonies were selected on MacConkey lactose agar (MC), Salmonella-Shigella (SS), and xylose lysine deoxycholate (XLD) agar, and Shigella species were identified by biochemical panel that consisted of EPM and MiLicitrate. A total of 36 isolates of Shigella spp. were identified.
The Shigella flexneri M90T was used as reference strains for comparison purposes. The antibiogram technique was performed as described by [14]. The following antibiotics were tested: amikacin (AMK), amoxicillin + clavulanic acid (AMC), ampicillin (AMP), ciprofloxacin (CIP), chloramphenicol (CLO), ceftriaxone (CRO), gentamicin (GEN), kanamycin (K), nalidixic acid (NAL), and tetracycline (TET).

Serological Tests. The Shigella strains were subcultured on MacConkey agar plates, and serological tests were performed by the slide agglutination method. The serotypes of all Shigella isolates were determined with commercially variable polyclonal antisera (Promicro-Brazil) against all Shigella serotypes, including S. sonnei 1 and 2, polyvalent S. flexneri, S. dysenteriae 2, and S. boydii 11.

PCR Assays. Each sample was submitted to PCR amplification with ten pairs of different primers (Table 1). For the detection of virulence genes, DNA was extracted from the samples using the phenol-chloroform method. Ten pairs of primers corresponding to the genus Shigella and two primers (uidA and invE) corresponding to invasion genes that are also found in Escherichia coli were used. The primers sequences used were obtained from Invitrogen, Brazil. Descriptions and the sequences of the PCR primers used in this study are given in Table 1. The primers for ipaH7.8 annealed a specific region that overlapped two contiguous genes, LRR and C-term-E3ligase genes. The primers for ipaBCD amplified a product from loci Ipa located upstream to $i p a B$ gene. Amplification was performed in a thermocycler (Eppendorf, Germany) by the methods described by Aranda et al. [13] and Faruque et al. [15]. The expected sizes of the amplicons were ascertained by electrophoresis in $1.5 \%$ agarose gel with an appropriate molecular size marker (Promega, Brazil).

The reactions were performed under the following conditions: $40 \mathrm{ng}$ of DNA, 5X buffer, $0.25 \mathrm{mM}$ dNTPs, $2.5 \mathrm{mM}$ $\mathrm{MgCl}_{2}, 5 \mu \mathrm{M}$ of each primer, $2.5 \mathrm{U}$ of high-fidelity Taq DNA polymerase (Invitrogen), and sterile deionized water in a total volume of $12.5 \mu \mathrm{L}$. PCR was performed in a thermocycler (Eppendorf) and consisted of the following steps: $94^{\circ} \mathrm{C}$ for 3 minutes, followed by 30 cycles of $94^{\circ} \mathrm{C}$ for 30 seconds, varying annealing temperatures for each gene (Table 1) for 45 seconds, and $72^{\circ} \mathrm{C}$ for 1 minute and 30 seconds. The final extension step was performed at $72^{\circ} \mathrm{C}$ for 10 minutes, followed by cooling to $4^{\circ} \mathrm{C}$. The fragments obtained were analyzed by horizontal electrophoresis on a $1 \%$ agarose gel at $100 \mathrm{~V}$ in TBE buffer. The gel was stained in a solution of ethidium bromide and visualized on a transilluminator.

16S rRNA Gene Sequencing. To confirm Shigella species identification, a region from $16 \mathrm{~S}$ rRNA gene located between $530^{\circ}$ to $1492^{\circ}$ nucleotides was amplified using the primers forward $5^{\prime}$-TGA CTG ACT GAG TGC CAG CMG CCG CGG-3' and reverse $5^{\prime}$-TGA CTG ACT GAG AGC TCT ACC TTG TTA CGM YTT- $3^{\prime}[16,17]$. The reaction $(50 \mathrm{mM}$ $\mathrm{MgSO}_{4}, 0.5 \mu \mathrm{L}$ of $10 \mathrm{mM}$ dNTPs, 5 pmol of each primer, 1.25 U Platinum Taq DNA polymerase High Fidelity, 10x buffer) consisted of three cycles $\left(1 \mathrm{x} 94^{\circ} \mathrm{C}\right.$ for $2 \mathrm{~min}$; $35 \mathrm{x} 94^{\circ} \mathrm{C}$ for $30 \mathrm{~s} ; 58^{\circ} \mathrm{C}$ for $30 \mathrm{~s}$; and $1 \times 68^{\circ} \mathrm{C}$ for $\left.1 \mathrm{~min}\right)$. After edition, the taxonomic affiliation was performed with "Ribosomal Database Project II" database. A minimum of 75\% similarity was considered for the encountered species. 
TABLE 1: The striking points employed for the detection of virulence markers of Shigella.

\begin{tabular}{|c|c|c|c|c|}
\hline Gene & Amplicon size (bp) & Primer & Annealing temperature ${ }^{\circ} \mathrm{C}$ & Reference \\
\hline \multirow{2}{*}{$e v t$} & \multirow{2}{*}{100} & CAACACTGGATGATCTCAG & \multirow{2}{*}{56} & \multirow{2}{*}[15]{} \\
\hline & & СССССТСАAСТGСТАATA & & \\
\hline \multirow{2}{*}{ ial } & \multirow{2}{*}{320} & CTGGATGGTATGGTGAGG & \multirow{2}{*}{60} & \multirow{2}{*}[18]{} \\
\hline & & GGAGGCCAACAATTATTTCC & & \\
\hline \multirow{2}{*}{$i p a B C D$} & \multirow{2}{*}{500} & GCTATAGCAGTGACATG & \multirow{2}{*}{59} & \multirow{2}{*}[15]{} \\
\hline & & ACGAGTTCGAAGCACTC & & \\
\hline \multirow{2}{*}{$i p a H$} & \multirow{2}{*}{933} & CTCGGCACGTTTTAATAGTCTGG & \multirow{2}{*}{59} & \multirow{2}{*}[19]{} \\
\hline & & GTGGAGAGCTGAAGTTTCTCTGC & & \\
\hline \multirow{2}{*}{ set1A } & \multirow{2}{*}{309} & TCACGCTACCATCAAAGA & \multirow{2}{*}{57} & \multirow{2}{*}[18]{} \\
\hline & & TATCCCCCTTTGGTGGTA & & \\
\hline \multirow{2}{*}{$\operatorname{set} 1 B$} & \multirow{2}{*}{147} & GTGAACCTGCTGCCGATATC & \multirow{2}{*}{57} & \multirow{2}{*}[18]{} \\
\hline & & ATTAGTGGATAAAAATGACG & & \\
\hline \multirow{2}{*}{$\operatorname{sen} / \operatorname{spD} \mathrm{D} 3$} & \multirow{2}{*}{799} & ATGTGCCTGCTATTATTTAT & \multirow{2}{*}{52} & \multirow{2}{*}[18]{} \\
\hline & & CATAATAATAAGCGGTCAGC & & \\
\hline \multirow{2}{*}{$\operatorname{virF}$} & \multirow{2}{*}{618} & TCAGGCAATGAAACTTTGAC & \multirow{2}{*}{60} & \multirow{2}{*}{ [19] } \\
\hline & & TGGGCTTGATATTCCGATAAGTC & & \\
\hline \multirow{2}{*}{ uidA } & \multirow{2}{*}{1487} & ATGCCAGTCCAGCGTTTTTGC & \multirow{2}{*}{54} & \multirow{2}{*}[20]{} \\
\hline & & AAAGTGTGGGTCAATAATCAGGAAGTG & & \\
\hline $\operatorname{inv} F$ & 766 & CGATAGATGGCGAGAAATTATATCCCG & 56 & {$[20]$} \\
\hline & 100 & CGATCAAGAATCCCTAACAGAAGAATCAC & 0 & {$[20]$} \\
\hline
\end{tabular}

\section{Results}

3.1. Diarrhea Symptoms Related to Shigella Infections. In the present study, thirty Shigella species were isolated from an etiologic study at which 1,339 children presenting with diarrhea over the period from August 2007 to July 2008. Shigella species were the fifth most common cause of diarrhea $(2.2 \%)$, that were led by enteropathogenic Escherichia coli in 837 cases (62.1\%), followed by 207 children with Rotavirus (15.4\%) and 192 with Salmonella species (14.3\%), and 34 cases of Yersinia species (2.5\%). Protozoa infection was observed in 46 cases: Entamoeba histolytica was found in 16 cases, 14 for Giardia lamblia, 13 for Entamoeba coli, and 3 for Balantidium coli. Twenty-four children had diarrhea associated with worms, 9 for Enterobius vermiculares, 9 for Ascaris lumbricoides, 4 for Ancylostoma species, and 2 for Trichiura trichuris. And still, the diarrhea etiology of one hundred ninety-nine children was unknown.

Monoinfections among major groups of enteropathogens were found, bacteria $(N=867)$, rotavirus $(N=39)$, and intestinal parasites $(N=8)$. Several coinfections were also found; thirteen children were infected by enteropathogenic bacteria, rotavirus, and intestinal parasites. Enteropathogenic bacteria coinfected with rotavirus in one hundred sixty-eight cases or with intestinal parasites in forty-five children were found.

Although rainfall in the region is seasonal [21], the temporal variation of cases of Shigella diarrhea did not fluctuate during the two rainfall stations, unlike the cases of diarrhea by other enteropathogens, which increased over the rainy season (Figure 1).
Thestudy was carried out with children aged $0-10$ years and as expected children over 2 years of age were moreaffected by Shigella $(P=0.002)$. The median of age of children affected by Shigella was 24 months (ranging from 14.2 to 47.2 ) differing from the group affected by other enteropathogens (14 months, ranging from 8 and 25). With respect to other epidemiologic factors, no difference was observed in both groups regarding the number and duration of diarrhea as well as the quality of the water consumed by population.

To characterize the main symptoms related to Shigella infections, initially the main diarrhea symptoms were compared among most prevalent etiologies (Table 2). The frequency of febrile children and dehydration signs were high and independent of etiology as expected. Similarly, the frequencies of children who have reported vomiting in clinical assessment were also high, except bacteria and rotavirus coinfected children whose frequency was slight higher $(P=$ 0.006). In contrast, low frequencies of blood in stool and fecal occult blood were found among children independent of etiology, with even lower frequencies among coinfected children by rotavirus and bacteria or rotavirus monoinfection children $(P=0.009)$.

Regarding four enterobacteria, independently the analyses were performed with same symptoms. The frequency of febrile children and dehydration signs were high and independent of bacteria species or others etiologic agents. Also in relation to blood in stool, low frequencies and none difference were found. Differences were found regarding vomiting and fecal occult blood. Among Shigella infected children, the frequency of those who have reported vomiting 


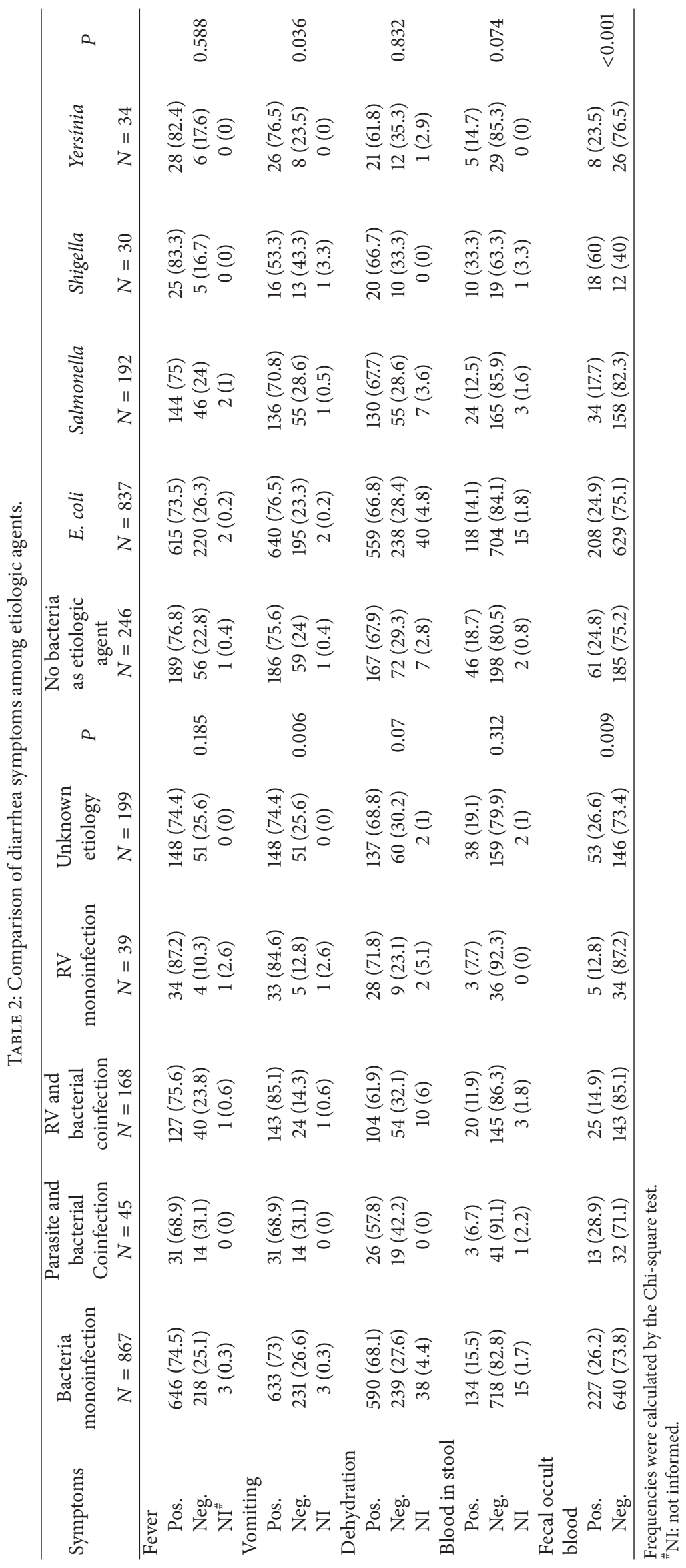




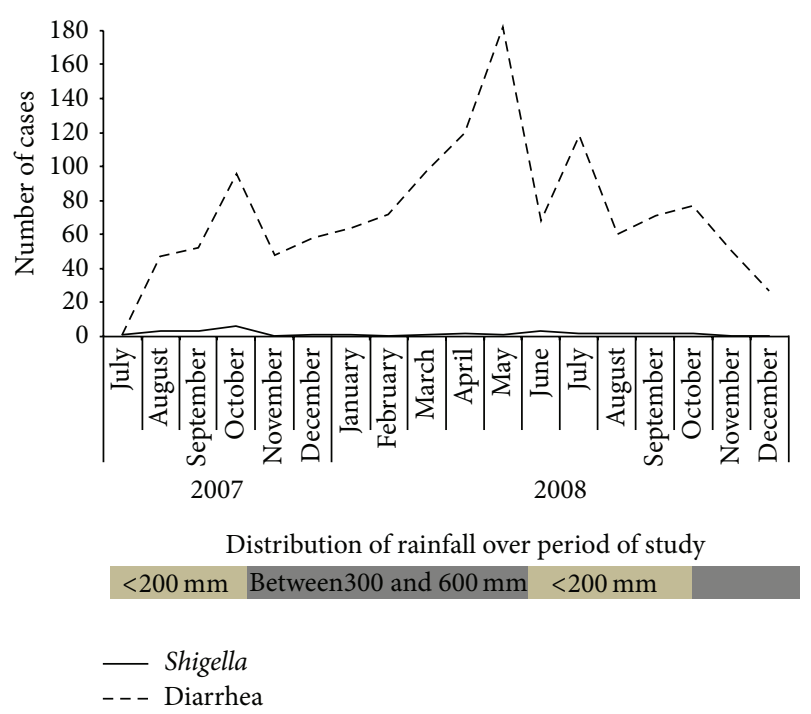

FIgURE 1: Temporal variation in diarrhea prevalence caused by Shigella and others enteropathogens. From August 2007 to December 2008,1346 children in the range of $0-10$ years old were admitted to hospital with diarrhea and they sought treatment at three hospitals in Manaus, in central of Brazilian Amazon. Stool specimens were collected at which Shigella as much as other enteropathogens were identified by classical methods. Distribution of rainfall over period of study is classified in two levels. Dark gray rectangles were the highest rate of rainfall (between 300 and $600 \mathrm{~mm}$ ). Light gray indicates the rainfall that was below $200 \mathrm{~mm}$ [21].

in clinical assessment was lower in relation to others bacteria $(P=0.036)$ including coinfection groups (Table 2).

The main difference concerned fecal occult blood, while with all etiologic agents the presence of traces of blood in stool had been less frequent, and the number of Shigella infected children was higher than expected $(P<0.001)$. Thus, only with one accurate method traces of blood in stool might associate with bacillary dysentery (Table 2).

3.2. Virulence Genes Related to Pediatric Shigellosis. The conventional and $16 \mathrm{~S}$ ribosomal gene confirmed 18 isolates of S. flexneri (8 S. sonnei, 2 S. dysenteriae, and 2 S. boydii isolates). The antimicrobial resistance was $80.0 \%(24 / 30)$ to tetracycline, $40.0 \%(12 / 30)$ to ampicillin, $30.0 \%(9 / 30)$ to chloramphenicol, $30.0 \%(9 / 30)$ to gentamicin, and $13.0 \%$ $(4 / 30)$ to both antibiotics amikacin and clavulanic acid. Thus, the resistance to ciprofloxacin and ceftriaxone was lower, with only $3 \%(1 / 30)$ of isolates presenting resistance. All isolates were sensitive to kanamycin and nalidixic acid (Table 3).

The detection of some major Shigella virulence genes gave intense amplicons with a clean background in each reaction according to conditions and PCR products (Table 1). The $i p a B C D$ gene was present in all isolates. Concerning others virulence genes, a vast genetic diversity was shown among isolates; $i \mathrm{paH}$ and set- $1 \mathrm{~A}$ genes were predominant in $63.3 \%$ of the isolates (19/30), followed by set-1B and ial in 56.7\% (17/30) of the isolates (Table 3). The sen/ospD3 (ShET-2), virF, and $i n v E$ genes were present at a frequency of $43.3 \%$, that is, in 13 isolates. Still, the evt was detected in 3 isolates (10.0\%), despite the low frequency of $S$. dysenteriae. The presence of evt gene and antimicrobial resistance of the isolates are shown together with the symptoms presented by children (Table 3 ). Some isolates carried set-1A but not set-1B, or vice versa.

The high frequencies of $i p a B C D$ and $i p a H$ genes could explain frequencies of fever, vomiting, and dehydration in infected children. Regardless of $v i r F$, invE, and evt genes due low frequencies, the analyses were performed with ial and (invasion-related processes) and set1- $A$ and set-1B. No association was found with fever, vomiting, or blood in stool with genes (data not shown).

In contrast, presence of blood traces in stool was related to shigellosis, and less common to all etiologic agents, two associations concerning Shigella enterotoxins were found. The Shigella species carrying sen/ospD3 gene for ShET-2 enterotoxin hemolysin were more frequent in children that had traces of blood in stools $(P=0.042)$. And a strong association was found with dehydration and set1- $B$ gene for Shigella enterotoxin $1(P<0.001)$ known for causing watery phase of diarrhea (Table 4). Thus, the PCR typing permitted us to connect particular virulence genes with symptoms of pediatric shigellosis.

\section{Discussion}

From a study in which the etiology of childhood diarrhea was investigated in 1,339 children from periphery of Manaus between August 2007 and July 2009, an intense and heterogeneous amount of enteropathogens found, from monoinfections to coinfections, were found in children from Manaus presenting with diarrhea. The lack of sanitation is a well-known problem in this city because less than $7 \%$ of the population has basic sanitation. Shigellosis is a disease that is one of the characteristics of areas like this, where it is difficult to maintain proper hygiene [1, 5, 12, 14, 15, 22-27]; thus, unsurprisingly the indicators of overall mortality and hospital morbidity due to diarrhea in Brazilian children are still worring [26].

What is interesting about findings on diarrhea-related symptoms is that independently if diarrhea was caused by mono- or coinfections, frequencies of febrile children, dehydration signs, and vomiting reported in clinical assessment were higher in all enteropathogens groups, and on the other hand frequencies of blood in stool among children were lower (Table 2). Moreover, detection of traces of blood in stool was in particular among Shigella-infected children. It is established that infection with Shigella can lead to the syndrome of bloody or watery diarrhea; nonetheless, studies, when the information of bloody diarrhea is reported by patients the frequencies, are divergent $[28,29]$. Therefore, in the present study, the presence of blood in stool by more accurate method could be evidenced as a particular Shigellosis.

Shigellosis is an acute intestinal infection, the symptoms of which can range from mild watery diarrhea to severe inflammatory bacillary dysentery [3]. The thirty isolates of Shigella species were confirmed by conventional and $16 \mathrm{~S}$ rRNA sequencing methods. Our data were consistent with observations in other regions of Brazil, with a predominance 


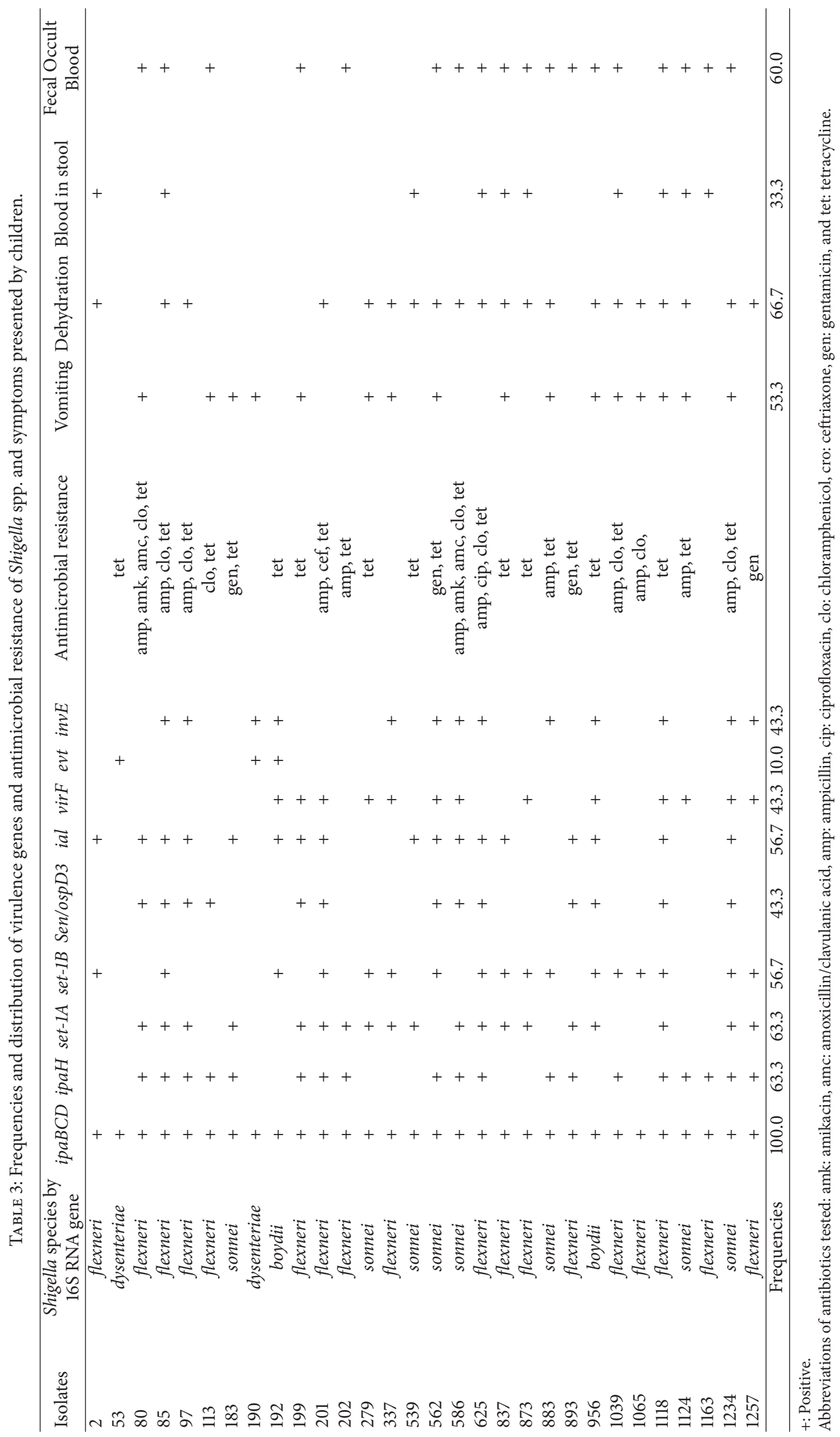


TABLE 4: Assessing of major Shigella virulence genes associated with main symptoms of dysentery bacillary.

\begin{tabular}{|c|c|c|c|c|c|c|c|c|c|c|}
\hline \multirow{2}{*}{ Virulence gene } & \multicolumn{2}{|c|}{ Dehydration } & \multirow{2}{*}{ Prevalence ratio } & \multirow{2}{*}{$\mathrm{CI}$} & \multirow{2}{*}{$P$} & \multicolumn{2}{|c|}{ Fecal occult blood } & \multirow{2}{*}{ Prevalence ratio } & \multirow{2}{*}{$\mathrm{CI}$} & \multirow{2}{*}{$P$} \\
\hline & Pos. & Neg. & & & & Pos. & Neg. & & & \\
\hline \multicolumn{11}{|l|}{ ial } \\
\hline Pos. & $12(60)$ & $5(50)$ & \multirow{2}{*}{1.15} & \multirow{2}{*}{$(0.68-1.94)$} & \multirow{2}{*}{0.705} & $11(61.1)$ & $6(50)$ & \multirow{2}{*}{1.2} & \multirow{2}{*}{$(0.65-2.22)$} & \multirow{2}{*}{0.821} \\
\hline Neg. & $8(40)$ & $5(50)$ & & & & $7(38.9)$ & $6(50)$ & & & \\
\hline \multicolumn{11}{|l|}{$i p a H$} \\
\hline Pos. & $16(80)$ & $8(80)$ & \multirow{2}{*}{1} & \multirow{2}{*}{$(0.53-1.88)$} & \multirow{2}{*}{0.999} & $16(88.9)$ & $8(66.7)$ & \multirow{2}{*}{2} & \multirow{2}{*}{$(0.62-6.42)$} & \multirow{2}{*}{0.184} \\
\hline Neg. & $4(20)$ & $2(20)$ & & & & $2(11.1)$ & $4(33.3)$ & & & \\
\hline \multicolumn{11}{|l|}{ set. $1 A$} \\
\hline Pos. & $14(70)$ & $5(50)$ & \multirow{2}{*}{1.35} & \multirow{2}{*}{$(0.74-2.47)$} & \multirow{2}{*}{0.425} & $12(66.7)$ & $7(58.3)$ & \multirow{2}{*}{1.16} & \multirow{2}{*}{$(0.61-2.19)$} & \multirow{2}{*}{0.712} \\
\hline Neg. & $6(30)$ & $5(50)$ & & & & $6(33.3)$ & $5(41.7)$ & & & \\
\hline \multicolumn{11}{|l|}{ set. $1 B$} \\
\hline Pos. & $16(80)$ & $1(10)$ & \multirow{2}{*}{3.06} & \multirow{2}{*}{$(1.34-6.97)$} & \multirow{2}{*}{$<0.001^{* *}$} & $10(55.6)$ & $7(58.3)$ & \multirow{2}{*}{0.96} & $(0.53-172)$ & 0.999 \\
\hline Neg. & $4(20)$ & $9(90)$ & & & & $8(44.4)$ & $5(41.7)$ & & & \\
\hline sen/ospD3 & & & & & & & & & & \\
\hline Pos. & $9(45)$ & $4(40)$ & 107 & $(065-077)$ & 0.999 & $11(61.1)$ & $2(16.7)$ & 205 & $(111-380)$ & $0.042 *$ \\
\hline Neg. & $11(55)$ & $6(60)$ & & & 0.999 & $7(38.9)$ & $10(83.3)$ & 2.05 & & \\
\hline
\end{tabular}

of S. flexneri, followed by S. sonnei or S. boydii, and finally $S$. dysenteriae $[12,15,22-27,30,31]$.

Here, some isolates showed resistance to ciprofloxacin and ceftriaxone, which are the antibiotics recommended by the WHO for shigellosis. In contrast, in others studies conducted in North and Northeast of Brazil, all Shigella were susceptible to ciprofloxacin and ceftriaxone [24-27]. The emergence of resistant Shigella strains might be explained by the indiscriminate use of antimicrobial drugs or treatment failure. Even so, these data contribute to the monitoring of regional strains to ensure the effective treatment of patients and monitoring of the emergence of new resistant strains [24].

Despite the fact that Shigella species are considered as the important cause of diarrheal disease, little is known about their genetic diversity worldwide. According to virulence genes examined, the Shigella isolates in this study had a vast genetic diversity. Among main Shigella virulence factors, the T3SS is essential for host cell invasion and intracellular survival [32-34]. The presence of IpaB, IpaC, and IpaD translocators could be detected using the upstream ipaB region as marker. Our data revealed all the isolates were positive for the $i p a B C D$ gene, as expected, whereas IpaB, $I p a C$, and IpaD are key factors of virulent Shigella [3]. Unlike $i p a B C D$, ipaH 7.8 was not very frequent. Because $i p a H 7.8$ is present on a large plasmid, this gene would be less stable to storage/subculturing than chromosomal genes encoded by $i p a H$. [35]. Similarly, ipaH was detected in almost all Shigella species from western Brazilian Amazon [25].

Contingency analysis revealed Shigella carrying sen/ ospD3 was associated to fecal occult blood $(P=0.042)$. ShET2 is known as an enterotoxin hemolysin that elicits inflammatory response during Shigella invasion. Our findings show that in cases of Shigella infection, ShET-2 contribute to induce intestinal injury induced by inflammation which would lead to bloody diarrhea $[3,8,9,11,36,37]$.
Regarding ShET-1 enterotoxin, contingency analysis showed Shigella isoletes that carry set-1B gene were associated with dehydration symptoms in children $(P<0.001)$. The ShET-1B subunit is enterotoxin, and according to experimental models, it alters the transport of water and electrolytes into the small intestine $[1,9,38,39]$. Our findings confirm ShET$1 \mathrm{~B}$ subunit as a potentially aggravating factor for dehydration in shigellosis.

\section{Conclusions}

We conclude that this PCR typing was able to identify irrespectively virulence genes in wild Shigella species, and our results showed vast genetic diversity of Shigella isolates. In addition, our study contributes to knowledge on particular symptoms of shigellosis associated with virulence genes, whose information about their roles are based on experimental models.

\section{Conflict of Interests}

The authors declare that there is no conflict of interests regarding the publication of this paper.

\section{Acknowledgments}

The authors thank the children as well as their parents or guardians as they have agreed to participate in our study. They also thank the staff of health that helped them in the hospitals and the laboratory technicians of Fiocruz Amazonia. This work was supported by grants from the Foundation to support the research of Amazonas state (FAPEAM), the Foundation to support the research of Minas Gerais state (FAPEMIG), the National Council for Scientific and Technological Development $(\mathrm{CNPq})$, and the Coordination of Improvement of Higher Education Personnel (CAPES). 


\section{References}

[1] S. K. Niyogi, "Shigellosis," Journal of Microbiology, vol. 43, no. 2, pp. 133-143, 2005.

[2] F. J. Martinez-Becerra, J. M. Kissmann, J. Diaz-Mcnair et al., "Broadly protective Shigella vaccine based on type III secretion apparatus proteins," Infection and Immunity, vol. 80, no. 3, pp. 1222-1231, 2012.

[3] G. N. Schroeder and H. Hilbi, "Molecular pathogenesis of Shigella spp.: controlling host cell signaling, invasion, and death by type III secretion," Clinical Microbiology Reviews, vol. 21, no. 1, pp. 134-156, 2008.

[4] K. A. Kane and C. J. Dorman, "VirB-mediated positive feedback control of the virulence gene regulatory cascade of Shigella flexneri," Journal of Bacteriology, vol. 194, no. 19, pp. 5264-5273, 2012.

[5] F. Grimont, M. Lejay-Collin, K. A. Talukder et al., "Identification of a group of Shigella-like isolates as Shigella boydii 20," Journal of Medical Microbiology, vol. 56, no. 6, pp. 749-754, 2007.

[6] B. Marteyn, A. Gazi, and P. Sansonetti, "Shigella: a model of virulence regulation in vivo," Gut Microbes, vol. 3, no. 2, pp. 104120, 2012.

[7] T. S. Coster, C. W. Hoge, L. L. van de Verg et al., "Vaccination against shigellosis with attenuated Shigella flexneri 2a strain SC602," Infection and Immunity, vol. 67, no. 7, pp. 3437-3443, 1999.

[8] P. J. Sansonetti, "Rupture, invasion and inflammatory destruction of the intestinal barrier by Shigella, making sense of prokaryote-eukaryote cross-talks," FEMS Microbiology Reviews, vol. 25, no. 1, pp. 3-14, 2001.

[9] J. P. Nataro, J. Seriwatana, A. Fasano et al., "Identification and cloning of a novel plasmid-encoded enterotoxin of enteroinvasive Escherichia coli and Shigella strains," Infection and Immunity, vol. 63, no. 12, pp. 4721-4728, 1995.

[10] C. M. Fernandez-Prada, D. L. Hoover, B. D. Tall, A. B. Hartman, J. Kopelowitz, and M. M. Venkatesan, "Shigella flexneri $\mathrm{IpaH}_{7.8}$ facilitates escape of virulent bacteria from the endocytic vacuoles of mouse and human macrophages," Infection and Immunity, vol. 68, no. 6, pp. 3608-3619, 2000.

[11] M. J. Farfán, C. S. Toro, E. M. Barry, and J. P. Nataro, "Shigella enterotoxin-2 is a type III effector that participates in Shigellainduced interleukin 8 secretion by epithelial cells," FEMS Immunology \& Medical Microbiology, vol. 61, no. 3, pp. 332-339, 2011.

[12] M. Angelini, E. G. Stehling, M. L. Moretti, and W. D. da Silveira, "Molecular epidemiology of Shigella spp strains isolated in two different metropolitam areas of Southeast Brazil," Brazilian Journal of Microbiology, vol. 40, no. 3, pp. 685-692, 2009.

[13] K. R. S. Aranda, U. Fagundes-Neto, and I. C. A. Scaletsky, "Evaluation of multiplex PCRs for diagnosis of infection with diarrheagenic Escherichia coli and Shigella spp," Journal of Clinical Microbiology, vol. 42, no. 12, pp. 5849-5853, 2004.

[14] A. W. Bauer, W. M. Kirby, J. C. Sherris, and M. Turck, "Antibiotic susceptibility testing by a standardized single disk method," American Journal of Clinical Pathology, vol. 45, no. 4, pp. 493496, 1966.

[15] S. M. Faruque, R. Khan, M. Kamruzzaman et al., "Isolation of Shigella dysenteriae type 1 and S. flexneri strains from surface waters in Bangladesh: comparative molecular analysis of environmental Shigella isolates versus clinical strains," Applied and Environmental Microbiology, vol. 68, no. 8, pp. 3908-3913, 2002.
[16] J. Borneman and E. W. Triplett, "Molecular microbial diversity in soils from eastern Amazonia: evidence for unusual microorganisms and microbial population shifts associated with deforestation," Applied and Environmental Microbiology, vol. 63, no. 7, pp. 2647-2653, 1997.

[17] J. E. Clarridge III, "Impact of 16S rRNA gene sequence analysis for identification of bacteria on clinical microbiology and infectious diseases," Clinical Microbiology Reviews, vol. 17, no. 4, pp. 840-862, 2004.

[18] K. A. Talukder, A. S. Mondol, M. A. Islam et al., "A novel serovar of Shigella dysenteriae from patients with diarrhoea in Bangladesh," Journal of Medical Microbiology, vol. 56, no. 5, pp. 654-658, 2007.

[19] O. G. Gómez-Duarte, J. Bai, and E. Newell, "Detection of Escherichia coli, Salmonella spp., Shigella spp., Yersinia enterocolitica, Vibrio cholerae, and Campylobacter spp. enteropathogens by 3-reaction multiplex polymerase chain reaction," Diagnostic Microbiology and Infectious Disease, vol. 63, no. 1, pp. 1-9, 2009.

[20] D. Müller, L. Greune, G. Heusipp et al., "Identification of unconventional intestinal pathogenic Escherichia coli isolates expressing intermediate virulence factor profiles by using a novel single-step multiplex PCR," Applied and Environmental Microbiology, vol. 73, no. 10, pp. 3380-3390, 2007.

[21] R. S. Macedo, W. G. Teixeira, G. C. Martins, A. C. G. Souza, O. C. Encinas, and L. M. B. Rossi, "Distribuição da precipitação pluviométrica e erosividade da chuva em eventos de alta intensidade na Província Petrolífera de Urucu, município de Coari, AM," III Reunião Cientifica da Rede CTPetro Amazônia, 2010, http://projetos.inpa.gov.br/ctpetro/IIIReuniao/ArtigosReuniao/PI2/Resumos/12MACEDO_TEIXEIRA_et\%20al.pdf.

[22] V. Wiwanitkit, "Sexually transmitted shigellosis," Sexuality and Disability, vol. 24, no. 1, pp. 69-71, 2006.

[23] E. C. Souza, M. B. Martinez, C. R. Taddei et al., "Etiologic profile of acute diarrhea in children in the city of São Paulo," Jornal de Pediatria, vol. 78, no. 1, pp. 31-38, 2002.

[24] G. Peirano, F. D. S. Souza, D. D. P. Rodrigues et al., "Frequency of serovars and antimicrobial resistance in Shigella spp. from Brazil," Memorias do Instituto Oswaldo Cruz, vol. 101, no. 3, pp. 245-250, 2006.

[25] T. Silva, P. A. Nogueira, G. F. Magalhães, A. F. Grava, L. H. P. da Silva, and P. P. Orlandi, "Characterization of Shigella spp. by antimicrobial resistance and PCR detection of ipa genes in an infantile population from Porto Velho (Western Amazon region), Brazil," Memorias do Instituto Oswaldo Cruz, vol. 103, no. 7, pp. 731-733, 2008.

[26] F. C. Bastos and E. C. B. Loureiro, "Antimicrobial resistance of Shigella spp. isolated in the state of pará, Brazil," Revista da Sociedade Brasileira de Medicina Tropical, vol. 44, no. 5, pp. 607610, 2011.

[27] M. D. R. C. M. Nunes, P. P. Magalhães, F. J. Penna, J. M. M. Nunes, and E. N. Mendes, "Diarrhea associated with Shigella in children and susceptibility to antimicrobials," Jornal de Pediatria, vol. 88, no. 2, pp. 125-128, 2012.

[28] I.-F. Huang, C.-H. Chiu, M.-H. Wang, C.-Y. Wu, K.-S. Hsieh, and C. C. Chiou, "Outbreak of dysentery associated with ceftriaxone-resistant Shigella sonnei: first report of plasmidmediated CMY-2-type AmpC $\beta$-lactamase resistance in $S$. sonnei," Journal of Clinical Microbiology, vol. 43, no. 6, pp. 26082612, 2005.

[29] P. Kalluri, K. C. Cummings, S. Abbott et al., "Epidemiological features of a newly described serotype of Shigella boydii," Epidemiology and Infection, vol. 132, no. 4, pp. 579-583, 2004. 
[30] K. L. Kotloff, J. P. Winickoff, B. Ivanoff et al., "Global burden of Shigella infections: implications for vaccine development and implementation of control strategies," Bulletin of the World Health Organization, vol. 77, no. 8, pp. 651-666, 1999.

[31] M. P. A. Penatti, L. M. Hollanda, G. Nakazato et al., "Epidemiological characterization of resistance and PCR typing of Shigella flexneri and Shigella sonnei strains isolated from bacillary dysentery cases in Southeast Brazil," Brazilian Journal of Medical and Biological Research, vol. 40, no. 2, pp. 249-258, 2007.

[32] C. Parsot, "Shigella type III secretion effectors: how, where, when, for what purposes?" Current Opinion in Microbiology, vol. 12, no. 1, pp. 110-116, 2009.

[33] C. J. Dorman and M. E. Porter, "The Shigella virulence gene regulatory cascade: a paradigm of bacterial gene control mechanisms," Molecular Microbiology, vol. 29, no. 3, pp. 677-684, 1998.

[34] P. J. Sansonetti and C. Egile, "Molecular bases of epithelial cell invasion by Shigella flexneri," Antonie van Leeuwenhoek, vol. 74, no. 4, pp. 191-197, 1998.

[35] K. L. Thong, S. L. L. Hoe, S. D. Puthucheary, and R. M. Yasin, "Detection of virulence genes in Malaysian Shigella species by multiplex PCR assay," BMC Infectious Diseases, vol. 5, article 8, 2005.

[36] A. Zychlinsky, K. Thirumalai, J. Arondel, J. Robert Cantey, A. O. Allprantis, and P. J. Sansonetti, "In vivo apoptosis in Shigella flexneri infections," Infection and Immunity, vol. 64, no. 12, pp. 5357-5365, 1996.

[37] T. L. Hale, "Genetic basis of virulence in Shigella species," Microbiological Reviews, vol. 55, no. 2, pp. 206-224, 1991.

[38] A. Fasano, F. R. Noriega, D. R. Maneval Jr. et al., "Shigella enterotoxin 1: an enterotoxin of Shigella flexneri 2a active in rabbit small intestine in vivo and in vitro," The Journal of Clinical Investigation, vol. 95, no. 6, pp. 2853-2861, 1995.

[39] A. Fasano, F. R. Noriega, F. M. Liao, W. Wang, and M. M. Levine, "Effect of Shigella enterotoxin 1 (ShET1) on rabbit intestine in vitro and in vivo," Gut, vol. 40, no. 4, pp. 505-511, 1997. 


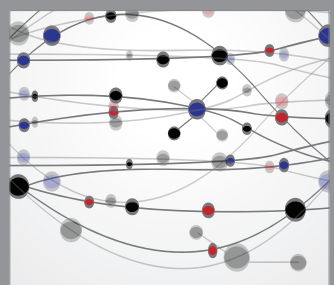

The Scientific World Journal
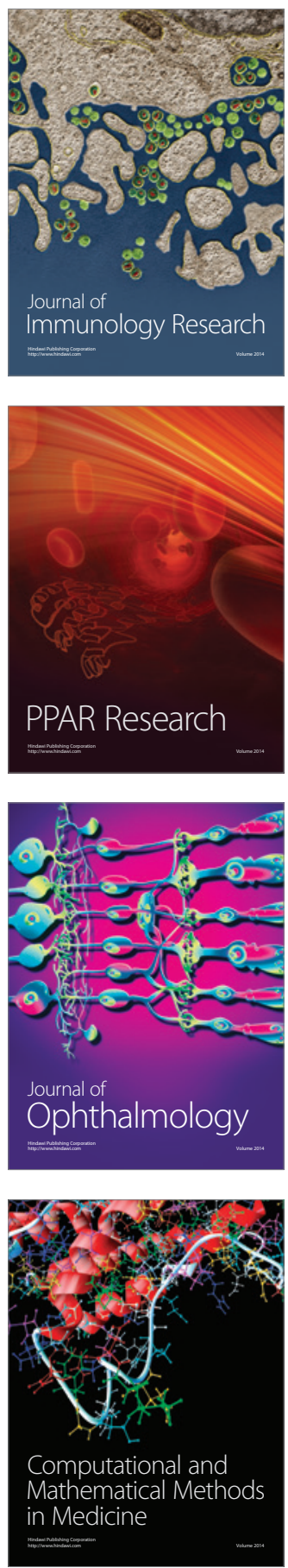

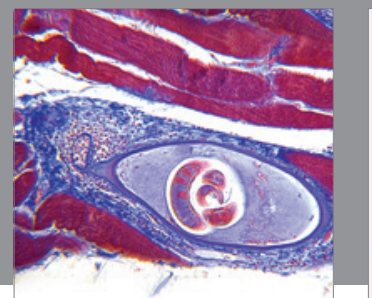

Gastroenterology

Research and Practice
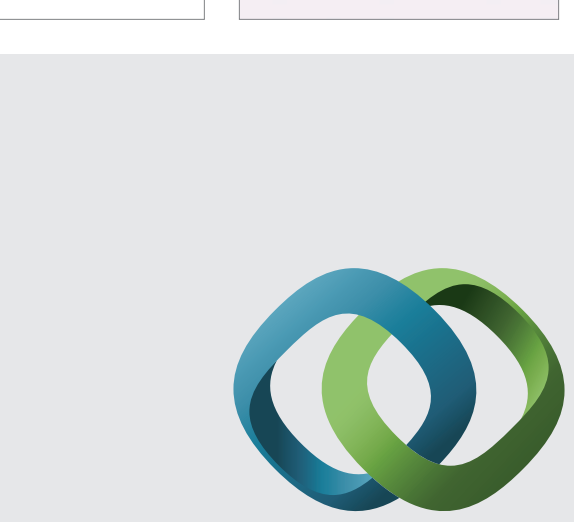

\section{Hindawi}

Submit your manuscripts at

http://www.hindawi.com
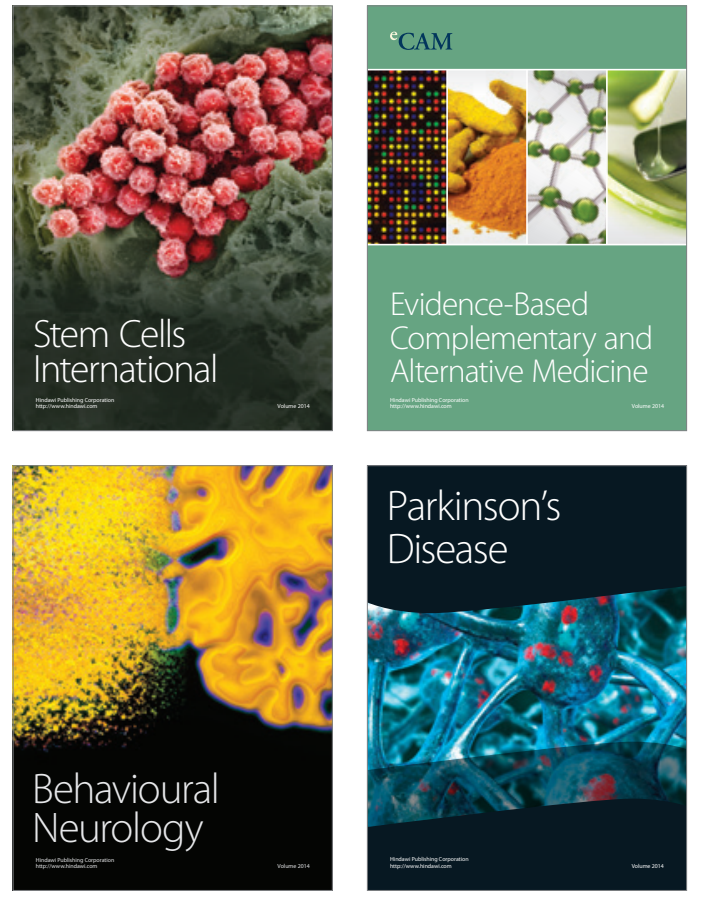
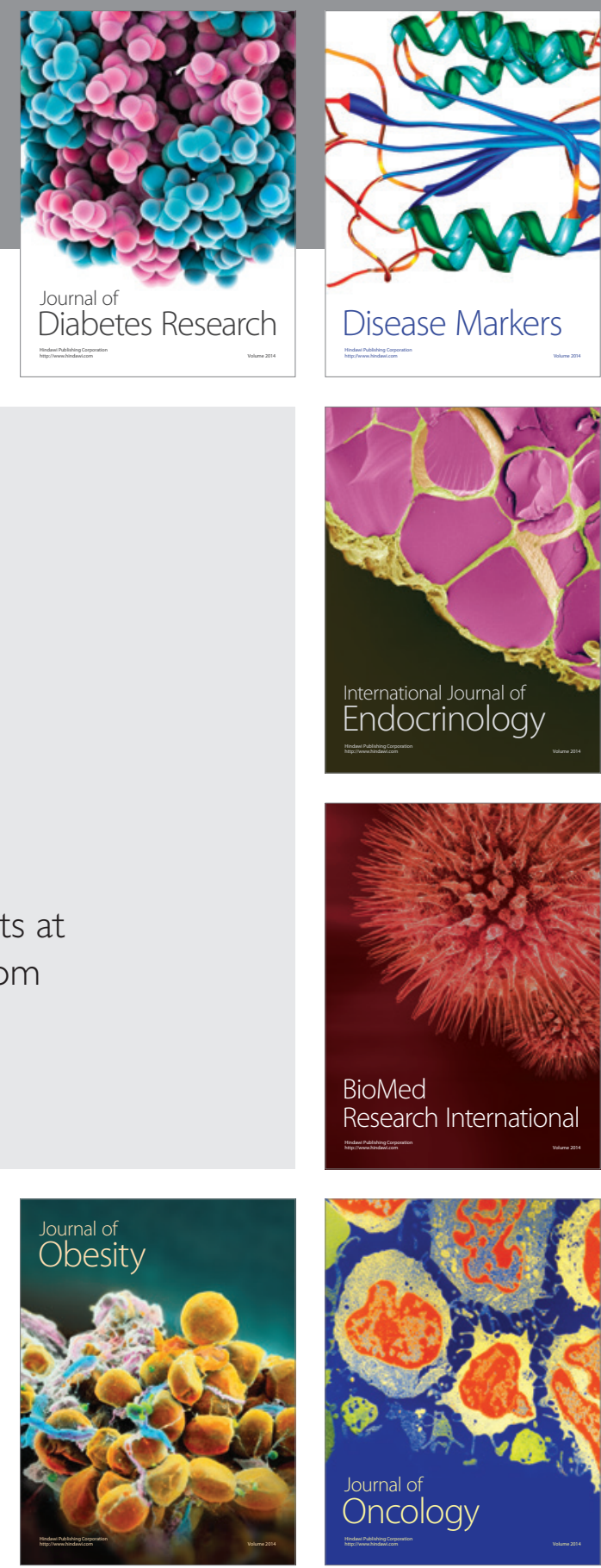

Disease Markers
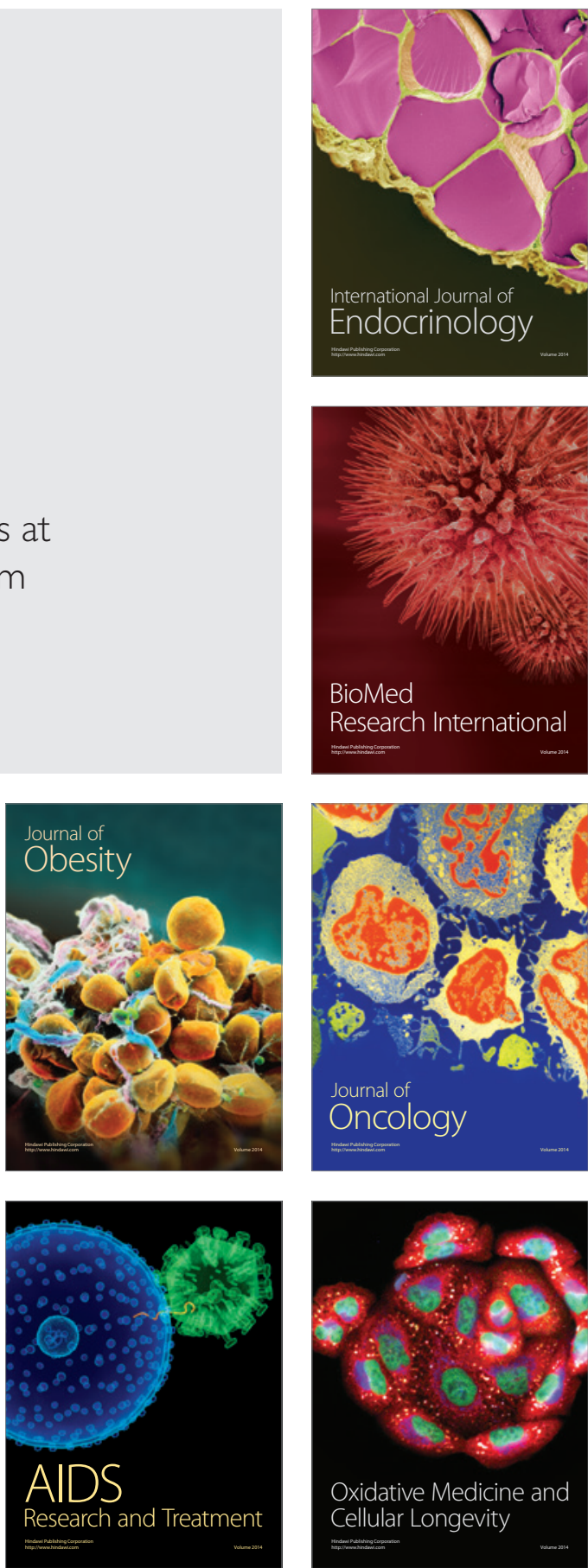